\title{
Corpo, técnica, cidade: artesanais entre pesquisa e cotidiano
}

Cuerpo, técnica, ciudad: artesanías entre pesquisa y cotidiano

Body, technique, city: craftworks between research and everyday life

\section{Eder Amaral e Silva}

Universidade Estadual do Rio de Janeiro, Rio de Janeiro, RJ, Brasil.

\section{Resumo}

Este texto constitui um modo de interrogar a produção do cotidiano enquanto plano de análise da experiência urbana. Para tornar possível esta análise, abordaremos inicialmente o cotidiano sob a perspectiva das técnicas que o constituem, tomando de empréstimo as noções de "técnicas da vida", presente em Georg Simmel, e de "técnicas do corpo" proposta por Marcel Mauss, a partir das quais se depreende uma concepção estética e política do cotidiano e do corpo; em seguida, passamos à inserção da problemática da cidade e seus espaços, aqui entendidos enquanto práticas, fazendo uso do que Michel Foucault nomeia por "heterotopia" e "contraconduta"; feito isso, evidencia-se o procedimento de pesquisa do cotidiano empreendido por Michel de Certeau, segundo o qual a análise modula, em sua própria constituição, o movimento das práticas que investiga; por fim, propõem-se algumas considerações a respeito do caráter performático da prática de pesquisa direcionada ao estudo do cotidiano.

Palavras-chave: Corpo, Técnica, Cidade, Cotidiano, Pesquisa.

\section{Resumen}

Ese articulo interroga la produción del cotidiano como uno plano de analisis de la experiencia urbana. Para que sea posible esa analisis, intentaremonos a pensar primeramente el cotidiano sob la perspectiva de las técnicas que lo constituyem, utilizandonos del termo "técnicas de la vida", de Georg Simmel, y de "técnicas del cuerpo" de Marcel Mauss, donde se tiran una concepción estética y política del cotidiano y del cuerpo; en seguida, pasamos a la inserción de una problemática sobre la ciudad y sus espacios, compreendidos acá como prácticas, haciendo uso de termos que Michel Foucault llama como "heterotopia" y "contraconducta"; despues, evidenciase el procedimento de pesquisa del cotidiano emprendido por Michel de Certeau, según el cual la analisis modula, en su própria consituición, el movimiento de las 
prácticas que se investiga; por conseguinte, proponense algunas consideraciones a respecto del caracter performático de la practica de pesquisa del cotidiano.

Palabras clave: Cuerpo, Técnica, Ciudad, Cotidiano, Pesquisa.

\begin{abstract}
This text constitutes a way of interrogate the production of everyday while a plan of analysis of urban experience. To enable this analysis, initially we discuss the everyday life from the perspective of the techniques which constitutes its, borrowing the notions of "techniques of life" found in Georg Simmel, and "body techniques" proposed by Marcel Mauss, from which enable an aesthetic and politic conception of everyday life and body; then we pass to insert the problems of the city and its spaces, understood while practices, using what Michel Foucault names as "heterotopia" and "counter-conduct"; done that, puts in evidences the researches procedures of everyday life undertaken by Michel de Certeau, according to which the analysis modules, in its own constitution, the movement of the practices which itself investigates; finally, proposes some considerations about the performative character of the practices of research directed to study the everyday life.
\end{abstract}

Keywords: Body, Technique, City, Everyday life, Research.

\title{
Um Laço e Alguns de Seus Nós
}

A vida cotidiana é constantemente associada à significação de um mundo coerente e à evidência de algo espontâneo, uma espécie de "atitude natural". Em Berger e Luckman (1985), esta faceta do cotidiano aparece perspectivada pela intencionalidade da consciência, aí evocada como marcador compreensivo das práticas humanas. "O que nos interessa aqui é o caráter intencional comum de toda consciência” (Berger \& Luckman, 1985, p. 37). Em defesa de um método fenomenológico, estes autores propõem um estudo puramente descritivo da vida cotidiana, de modo que os processos sociais sejam tomados tal qual aparecem para a consciência - que seja dito, a consciência aí é sempre "consciência de" alguma coisa, não existe em si mesma, mas sempre a partir de uma tendência ou direcionamento para determinados objetos (Berger \& Luckman, 1985).

Sob o argumento durkheimiano, Berger e Luckman pinçam da realidade que estudam seu possível ordenamento geral, operando uma "objetivação" dos objetos: "A realidade da vida cotidiana aparece já objetivada, isto é, constituída por uma ordem de objetos que foram 
designados como objetos antes de minha entrada em cena" (Berger \& Luckman, 1985, grifo dos autores). Entretanto, o mesmo cotidiano que presentifica esta condição implica intervenções de novas significações, por meio do que a "interação" dos indivíduos se faz instrumento da construção social de sentidos para a realidade (Berger \& Luckman, 1985). Nesta perspectiva, o modo de pensar o cotidiano toma como ponto de referência a tipicidade das relações cotidianas. A menos que ocorra algum desvio, nada escapa aos tipos convencionados, às regularidades que se impõem na rotina. A oposição entre um funcionamento - os autores chamam de "setor" - "normal" e outro "problemático" do dia a dia, manifesta a dificuldade (seja nas ciências humanas, seja no senso comum) de pensar a vida cotidiana, a rotina e suas práticas como inerentemente problemáticas. A crise ou o problema são tomados quase sempre como "novidade" exterior, aquilo que obrigaria a sair da rotina. Mantém-se o problemático sempre fora dela, como seu contrário. E aí há uma questão importante:

Então o quotidiano seria o que no dia a dia se passa quando nada se parece passar. Mas só interrogando as modalidades através das quais se passa o quotidiano as modalidades que caracterizam ou representam a vida passante do quotidiano
- nos damos conta de que é nos aspectos anódinos da vida social, no «nada de novo» do quotidiano, que encontramos condições e possibilidades de resistência que alimentam sua própria rotura (Pais, 2007, p. 30).

Sob este ponto de vista, a rotina é, de fato, imprescindível à vida social. Entretanto, insiste em explorar as rupturas da rotina na própria rotina. Seus tons, cheiros, ritmos variam "numa transitoriedade que não deixa grandes marcas de visibilidade" (Pais, 2007, p. 30). O cotidiano enquanto "campo vivo" requer um modo de atenção diferenciado, que se interessa pelos restos, pelos "submundos feitos dos desperdícios e rebotalho do pensamento logocêntrico" (Pais, 2007, p. 34). O cotidiano não pré-existe ao ato de problematização que o produz no pensamento.

\footnotetext{
Quer isto dizer que o cotidiano não é uma parcela isolável do social. Com efeito, o quotidiano não pode ser caçado a laço quando cavalga diante de nós na exacta medida em que o quotidiano é o laço que nos permite «levantar caça» no real social, dando nós de inteligibilidade ao social (Pais, 2007, p. 32).
}

Uma possível rota de conhecimento. Se o cotidiano é assim entendido, passamos a dispor não de um objeto de estudo privilegiado, mas de um 
plano de coordenadas múltiplas, um campo problemático que se constitui ao passo em que o percorremos. Não um objeto a ser laçado, mas o próprio laço, matéria da procura, da pesquisa. O cotidiano se faz como esta rota ou plano de análise, circunstanciado aqui por uma articulação entre corpo, técnica e cidade - três dos muitos nós que se envolvem neste laço derivada de contribuições do pensamento de Simmel, Mauss, Foucault e Certeau.

\section{O Cotidiano e Suas Manhas}

Há um detalhe no célebre texto de Georg Simmel, As grandes cidades e a vida do espírito (2005), que pede passagem se a leitura envereda para o caminho das práticas cotidianas na cidade. Duas discretas aparições no texto são turvadas pela densa exploração dos aspectos psíquicos e sociológicos da experiência metropolitana, pela tipificação da atitude urbana por excelência, o blasé. Trata-se da expressão técnica da vida. Ainda que rareie sua presença no texto da conferência, parece haver nela o indício de importantes questões para pensar o cotidiano urbano.

Embora Simmel não se dedique a definir conceitualmente a expressão, pelo modo como aparece no texto ela contrai uma polissemia: remete, por um lado, ao plano das ações cotidianas matizadas pelas particularidades da proliferação dos modos de viver na cidade. Frente à expressiva racionalização do tempo, do espaço e das relações sociais - movimento que faz da urbanização signo da segunda metade do século XIX -, a invenção e difusão de procedimentos que permitam ao homem moderno dar conta da cidade ao seu modo, na medida do seu quinhão, manifestam o caráter ao mesmo tempo capilar - cada modo de vida contará com suas técnicas e global - é preciso, em todo caso, desenvolvê-las para viver na cidade. $\mathrm{O}$ duplo tom das técnicas da vida, especificidade e exigência geral, percute o processo que consolida sua forma na multiplicidade dos negócios urbanos (ocupações, produtos, serviços, organizações...) e na "intensificação da vida nervosa", como bem assinala Simmel na clássica conferência.

Por outro lado, a expressão parece estar aberta a sentidos subterrâneos ao primeiro, constituindo-o sem, no entanto, esgotarem-se nele. Ao falar em técnica da vida, Simmel dá vazão à possibilidade de que tal técnica figure não apenas como resposta às exigências do cotidiano citadino, mas também como modo de apropriação e singularização da experiência urbana. Não por acaso, o sociólogo alemão se interessa pelos fenômenos cotidianos, marcados pela "superficialidade", nos quais percebe a 
oportunidade de analisar "o sentido e o estilo da vida" (Simmel, 2005, p. 580.). As técnicas da vida apresentam-se, segundo esta perspectiva, como pontuais e efêmeros procedimentos de enfrentamento da rotina. Enfrentar a rotina, no sentido reativo de suportá-la, mas também - daí o ponto nevrálgico da ideia - para nela interferir, dela tirar proveito em modalidades as mais diversas, compondo a miscelânea dos estilos de vida que avulta na cidade.

Este enfrentamento ativo da rotina, materializado em modos de pensar, sentir, agir e dizer, pressupõe que se disponha primordialmente do próprio corpo como instrumento das técnicas da vida. Sob esta leitura, a expressão simmeliana produz ressonância com as técnicas do corpo, assinaladas por Marcel Mauss como sendo "as maneiras pelas quais os homens, de sociedade a sociedade, de uma forma tradicional, sabem servir-se de seu corpo" (Mauss, 2003, p. 401). De que corpo fala Mauss? Do corpo físico-biológico, individual, mas afirmando enfaticamente que este corpo não é "natural". Decorre daí o contorno analítico que a concepção de técnicas corporais carrega.

No curto e rico ensaio que concentra as ideias de Mauss sobre estas técnicas, vemos um breviário de usos que o homem faz do seu corpo, em certa medida orientados pela tradição e pela eficácia inerente a estes procedimentos, configurando um domínio técnico no qual não há outro "instrumento" que não o próprio corpo humano. Ora, Mauss adverte que é preciso escapar ao engodo da suposição de que só há técnica onde há instrumento. Trata-se, ao contrário, de um modo de pensar em que o processo e o produto se confundem, ou melhor, não se dissociam, são necessariamente imbricados um no outro, no que Mauss constitui uma vizinhança com a concepção ontogenética da técnica (Escóssia, 1999). O corpo individual é constantemente marcado pela educação, pelos ritos, pelos pequenos acontecimentos do dia a dia que produzem corpo e subjetividade indissociadamente. “A posição dos braços e das mãos enquanto se anda é uma idiossincrasia social, e não simplesmente um produto de não sei que arranjos e mecanismos puramente individuais" (Mauss, 2003, p. 404).

Para Mauss, a técnica pressupõe transmissão e, portanto, uma tradição. Deve também produzir efeitos, ser eficaz, sem o quê não caberia falar de técnica. Assim, o corpo humano enquanto objeto e meio técnico do homem por excelência, é permanentemente assinalado por atos mudos que só se enunciam pelos movimentos, atividades e repousos do corpo. É toda uma série de ritmos, atitudes e posturas: posições da mão, jeitos de andar, formas de corrida, de nado, da caça, 
os modos de olhar, as "manhas" de ingestão, de controle do sono etc. No infinito destas miúdas práticas cotidianas, protegidas por sua própria insignificância (Lévi-Strauss, 2003), o corpo humano torna-se um compósito vivo do corpo social.

Essa adaptação constante a um objetivo físico, mecânico, químico (por exemplo, quando bebemos) é efetuada numa série de atos montados, e montados no indivíduo não simplesmente por ele próprio mas por toda a sua educação, por toda a sociedade da qual faz parte, conforme o lugar que nela ocupa (Mauss, 2003, p. 407-8).

Não há exagero em afirmar que prefiguram neste ensaio de Mauss diversos "programas" de pesquisa realizados no correr do século XX e ainda por vir. Da antropologia à psicanálise, da educação à política, é possível estabelecer profícuas possibilidades de apropriação do estudo das técnicas do corpo. Se o corpo humano é assim "montado", conformado, produzido, torna-se premente a colocação do problema político que desponta no escopo de uma análise das técnicas do corpo ao longo da história das sociedades. A desnaturalização do corpo humano permite apreendê-lo como produto de relações de força que atravessam a cultura sob as formas da educação, da crença, da afetividade, da sensibilidade, do discurso.
É toda uma operatória dos usos do corpo, em que o corpo humano deixa de ser oposto ou refratário ao corpo social. Por esta perspectiva, as técnicas do corpo não podem ser dissociadas das técnicas da vida, uma vez que o corpo é permanentemente assinalado como objeto de intervenções políticas. Aqui Simmel e Mauss se reencontram, na articulação entre a pesquisa das técnicas corporais e os modos de vida: "Há razão de estudar todos os modos de adestramento, de imitação e, particularmente, essas formas fundamentais que podemos chamar $o$ modo de vida, o modus, o tonus, a 'matéria', as 'maneiras', a 'feição'” (Mauss, 2003, p. 411, grifos do autor).

Técnicas do sono e da vigília, da atividade e do movimento, do uso da força, dos cuidados corporais, do consumo, da alimentação, do sexo, da medicação... Aquilo que parece haver de mais "natural" na vida cotidiana do homem passa aí por uma problematização indissociável da experiência social. A dimensão individual que anima estas práticas só se concretiza na constituição de modos de viver. Implica, assim, uma transmissão e um uso da tradição, ainda que para subvertê-la ou reinventá-la. 


\section{A Cidade Praticada}

O espaço é uma categoria frequentemente negligenciada pelo pensamento filosófico moderno (Foucault, 1984). Nos giros do final do século XVIII, inicia-se a instauração metódica de políticas dos espaços, sustentadas por discursos e técnicas resultantes de descobertas científicas daquele século. Por esta dupla apropriação - por uma tecnologia política e por uma prática científica -, a filosofia perde o "direito" de pensar o espaço e passa a se dedicar restritivamente à interrogação do tempo, implicando uma desqualificação e certa resistência, por parte da filosofia que desde Kant nos alcança, em relação às questões que envolvem o espaço (Foucault, 1984).

Ao situar historicamente o "abandono" do problema do espaço pela filosofia, Foucault o reposiciona em sua investigação através de uma articulação necessária com problema político: o espaço deixa de ser pensado como mero substrato ou fronteira física (o solo, o ar etc.), um dado imóvel e inerte (sítio localizável) para ser concebido a partir das estratégias, saberes e poderes que $\mathrm{o}$ constituem (Foucault, 1984). Neste sentido, seu modo de abordar o espaço não apenas o reinsere no plano filosófico como determina um direcionamento históricopolítico para esta reinserção:
Seria preciso fazer uma "história dos espaços" - que seria ao mesmo tempo uma "história dos poderes" - que estudasse desde as grandes estratégias da geopolítica até as pequenas táticas do habitat, da arquitetura institucional, da sala de aula ou da organização hospitalar, passando pelas implantações econômico-políticas (Foucault, 1984, p. 212, grifos do autor).

É importante antecipar que a perspectiva foucaultiana não se destina a uma orientação utopista do espaço, na qual esta categoria se revestiria de um caráter revolucionário intrínseco. Foucault assinala um contraste entre esta posição sem lugar que tipifica as utopias e, de outra parte, as contraposições que desassossegam a linguagem, interferindo naquilo que existe efetivamente, condição que faz vacilar a norma sob a impossibilidade de ordenar o mundo segundo as generalidades e binarismos dos códigos. A esta segunda disposição, Foucault denomina heterotopia.

As utopias consolam: é que, se elas não têm lugar real, desabrocham, contudo, num espaço maravilhoso e liso; abrem cidades com vastas avenidas, jardins bem plantados, regiões fáceis, ainda que $o$ acesso a elas seja quimérico. As heterotopias inquietam, sem dúvida porque solapam secretamente a linguagem, porque impedem de nomear isto e aquilo, porque fracionam os nomes comuns ou os emaranham, porque arruínam de antemão a 
"sintaxe", e não somente aquela que constrói as frases - aquela, menos manifesta, que autoriza "manter juntos" (ao lado e em frente umas das outras) as palavras e as coisas. Eis por que as utopias permitem as fábulas e os discursos: situam-se na linha reta da linguagem, na dimensão fundamental da fábula; as heterotopias [...] dessecam o propósito, estancam as palavras nelas próprias, contestam, desde a raiz, toda possibilidade de gramática [...] (Foucault, 1999c, p. XIII, grifos do autor).

O desvio silencioso do instituído, a contestação não anunciada é o aspecto que modula a incomum potência política das heterotopias. São "protestos" sem palavra de ordem, acontecimentos que contaminam a linguagem ali mesmo onde ela exerce seu domínio. Elas cultivam estranheza onde o Mesmo impera. Entretanto, seus efeitos extrapolam o campo da linguagem ao pensar esta outra potência do espaço. Numa conferência proferida a arquitetos e urbanistas (Foucault, 2006), Foucault coloca em perspectiva a história da constituição dos espaços em que a vida humana acontece. Na ocasião, é retomada a distinção entre utopias e heterotopias. Ao tratar do pensamento contemporâneo na relação entre estes espaços e os sentidos que lhes atribuímos, o filósofo constata que esta relação tem sido referida quase sempre a um certo espaço de dentro. Seria preciso pensar num espaço de fora, sobre o qual Foucault diz:

[...] o que me interessa são, entre todos esses posicionamentos, alguns dentre eles que têm a curiosa propriedade de estar em relação com todos os outros posicionamentos, mas de um tal modo que eles suspendem, neutralizam ou invertem o conjunto de relações que se encontram por eles designadas, refletidas ou pensadas (Foucault, 2006, p. 414).

Enquanto o espaço de dentro corresponde à caracterização dos seus possíveis atributos, o espaço de fora se constitui por determinadas posições. A associação deste espaço à ideia de posicionamento sinaliza um traço forte do pensamento foucaultiano, a saber, a primazia das práticas. É pensando o espaço como um conjunto de práticas - e não como um dado, um vazio em que supostamente nos movimentamos - que encontramos as primeiras articulações entre espaço e cotidiano. $\mathrm{O}$ espaço de fora é, neste sentido, um espaço praticado.

As heterotopias seriam, então, estes espaços praticados, estes contraposicionamentos reais que perturbam o estabelecido na sua existência concreta. Se as utopias protestam e profetizam além-mundo, as heterotopias desfiguram e põem em crise ali mesmo, silenciosamente. Trata-se da passagem de 
uma busca por "outro mundo" para um pensamento de

[...] lugares reais, lugares efetivos [...] que são espécies de contraposicionamentos, espécies de utopias efetivamente realizadas nas quais $[. .$.$] todos os posicionamentos$ reais que se podem encontrar no interior da cultura estão ao mesmo tempo representados, contestados e invertidos, espécies de lugares que estão fora de todos os lugares, embora eles sejam efetivamente localizáveis (Foucault, 2006, p. 415, grifo nosso).

É preciso manejar com certa prudência este conceito. $\mathrm{O}$ risco de uma captura da heterotopia pela gravidade da ideia de "revolução" exige atenção redobrada ao que diz Foucault: estes contraposicionamentos já funcionam por toda parte, não se explicam pela intencionalidade (o que impede "pretensões" de totalizá-los) e não contraem qualquer possibilidade de um programa. Foucault não está oferecendo uma "alternativa" à utopia, são posições completamente diferentes. As heterotopias são práticas anônimas, de um anonimato absoluto que se desdobra em ausência de projeto.

A importância desta advertência está em reservar o sentido do conceito precisamente às práticas que desviam de qualquer necessidade de "mudar o mundo". O campo problemático que aí emerge é o da vida cotidiana, dos espaços e das práticas que trapaceiam a rotina sem a impedir de efetuar seu ritmo, mas ao mesmo tempo colocando-lhe em crise. Esta crise heterotópica sinaliza outro aspecto do espaço praticado, a saber: não obstante a "discrição" destas práticas, elas implicam um campo de tensões, disputas, conflitos. Não há heterotopia que se constitua alheia às relações de força e aos jogos de poder, o que permite uma entrada no plano da política coincidente com o problema da experiência urbana.

Sob este aspecto, há outro elemento importante para pensar esta operatória do espaço, a noção de contraconduta. Foucault emprega este termo ao tratar de modos de enfrentamento cujas pontas nos alcançariam desde os séculos XV e XVI, a partir do contexto da Reforma, e que indicariam uma crise política a qual incide diretamente sobre a experiência ocidental da subjetividade (Foucault, 1995a). Na análise foucaultiana, a prevalência desta crise, conjugada à emergência de novas formas de luta na contemporaneidade, assume os contornos de um novo combate, em que se efetuam combinações cada vez mais sofisticadas entre técnicas de individualização e procedimentos de totalização. "Isto se deve ao fato de que o Estado moderno ocidental integrou, numa nova forma política, uma antiga tecnologia 
de poder, originada nas instituições cristãs" (Foucault, 1995a, p. 236). Sai de cena o poder pastoral, entra o Estado moderno; declina o fiel, insurge o homem ordinário.

Falar em contraconduta seria, para Foucault, uma tentativa provisória de escapar dos mal-entendidos em torno do conceito de "resistência". O desconforto advém da necessidade de precisar um conjunto de práticas que não poderiam ser totalmente abarcadas pelo sentido da revolta, da desobediência ou da dissidência:

Queria simplesmente colocar agora um problema de puro e simples vocabulário. Aquilo a que chamei há pouco de resistências, recusas, revoltas, será que não poderíamos encontrar uma palavra para [o] designar? Como designar esse tipo de revoltas, ou antes, essa espécie de tramas específica de resistência a formas de poder que não exercem a soberania e que não exploram, mas que conduzem? (Foucault, 2008, p. 263-4, grifo nosso).

A administração da cidade como vetor de intervenções políticas no cotidiano também aparece como um dos temas do curso ministrado por Foucault entre 1977 e 1978, intitulado Segurança, Território, População (2008). Encontramse neste curso pistas do funcionamento das estratégias sutis de condução da vida que marcam a organização da cidade moderna.
Mais do que a autoridade soberana ou a exploração da força de trabalho, a cidade se converte em palco de práticas de administração da vida. Mais que a racionalização dos tráfegos, a setorização da economia e do comércio, o esquadrinhamento do espaço habitado, emerge aí um investimento cada vez mais incisivo nos processos de subjetivação, o que se estende aos discursos de cidadania, as campanhas de "bom uso" da cidade, a construção dos mitos que orientam o olhar dos citadinos.

$\mathrm{Na}$ esteira deste processo, as contracondutas desfigurariam os procedimentos empregados para conduzir a vida. Como as heterotopias, estas também seriam raras, anônimas, discretas. Foucault ressalta que a escolha desta palavra também atende à tentativa de evitar a substantivação destas práticas, o que daria em mais um mal entendido, a saber, aquele que moraliza as práticas e santifica, heroiciza ou condena seus praticantes (Foucault, 2008). Com esta cautela, Foucault mais uma vez insiste no caráter coletivo das práticas:

\footnotetext{
Além disso, essa palavra "contraconduta" - talvez também permita evitar certa substantificação que a palavra "dissidência" permite. Porque de dissidência vem "dissidente", ou o inverso, pouco importa - em todo caso, faz dissidência quem é dissidente. Ora, não
} 
estou muito certo de que essa substantificação seja útil. Temo inclusive que seja perigosa [...]. Temos aí um procedimento de santificação ou de heroização que não me parece muito válido. Em compensação, empregando a palavra contraconduta, é sem dúvida possível, sem ter de sacralizar como dissidente fulano ou beltrano, analisar os componentes na maneira como alguém age efetivamente no campo muito geral da política ou no campo muito geral das relações de poder (Foucault, 2008, p. 266, grifo nosso).

Há uma relação crítica entre as heterotopias e as contracondutas, relação que parece importante para pensar as práticas cotidianas que compõem a experiência urbana e que se desdobra em dois sentidos: em primeiro lugar, a cidade contemporânea, exaustivamente caracterizada sob a imagem do espaço planejado e administrado, é a mesma cidade cravejada de espaços que distorcem a medida e desarranjam a gestão. Ora, estes "espaços outros" não são exteriores à racionalidade investida no urbano, pelo contrário, eles se presentificam nesta ordem, mas colocando-lhe em questão por sua condição de espaços praticados; aí está a grande diferença desta concepção de espaço, que não se confunde com o substrato físico, mas corresponde a rede de relações que o engendra. $O$ segundo sentido desta relação remete ao modo como o planejamento e administração da cidade se convertem em planejamento e administração da vida - aquilo que Foucault chama de "biopolítica" (Foucault, 2008.) - e que, embora produza uma série de efeitos positivados, não deixa de ser contestado (contraconduzido) anonimamente no cotidiano da cidade. Como pensar o anonimato destas teimosias?

\section{As Teimosias Silenciosas}

Com Michel de Certeau o cotidiano insurge em astúcias e desvios. Antes de tudo, é preciso lembrar que Certeau faz uma crítica - generosamente incisiva - à leitura foucaultiana do panóptico em Vigiar e Punir (1987), dedicando-se em especial à concepção de disciplina formulada por Foucault ${ }^{1}$. Na "Introdução Geral" do primeiro volume de A invenção do cotidiano, Certeau explicita a contraposição de escopo do seu estudo em relação às análises das tecnologias e estratégias de regulação contemporâneas:

Se é verdade que por toda a parte se estende e se precisa a rede da 'vigilância', mais urgente ainda é descobrir como é que uma sociedade inteira não se reduz a ela: que procedimentos populares (também 'minúsculos' e cotidianos) jogam com os mecanismos da disciplina e não se conformam com ela a não ser para alterá- 
los; enfim, que 'maneiras de fazer', formam a contrapartida, do lado dos consumidores (ou dominados?), dos processos mudos que organizam a ordenação sociopolítica. [...] Esses modos de proceder e essas astúcias de consumidores compõem, no limite, a rede de uma antidisciplina que é o tema deste livro (Certeau, 2009, p. 40-1).

É claro que pela precisão do enfoque e pelo interesse de Certeau em analisar "o outro lado" da história - as práticas microbianas que resistem às estratégias do Estado e do Capital, mantendo mesmo sob seu "domínio" astuciosas artes de fazer, dizer e pensar - o recurso a conceitos como os de heterotopia e contraconduta acaba por enveredar numa trilha subterrânea entre os dois pensadores, um tanto diversa daquela que se depreende no imediato da leitura de $\mathrm{A}$ invenção do cotidiano. Daí que neste texto eles apareçam mais próximos do que convencionalmente se os dispõe.

A vizinhança problemática entre Foucault e Certeau oferece ao menos estas duas circunstâncias de encontro: em primeiro lugar, um adversário seletivo, que situa sua relação com o pensamento de Foucault (e também de Bourdieu) no plano de uma "antiafinidade eletiva" (Giard citado por Certeau, 2009, p. 17), uma seleção que acusa no mesmo passo o distanciamento necessário para elaborar sua própria análise, balizado por contribuições de trabalhos que transitam num campo problemático se não comum, pelo menos adjacente. Dessa curiosa política de vizinhança, Certeau desenvolve uma "colaboração" indireta que impulsiona sua empreitada, de tal forma que estas "influências" se presentificam - seja nos direcionamentos da pesquisa, seja na sua escrita - pelas alterações e avigoramentos que provocam (Certeau, 2009).

Em segundo lugar, a via dos conceitos que se imbricam. Diante do fato histórico de que as pesquisas que resultaram em Vigiar e Punir e A invenção do cotidiano (publicados em 1975 e 1980, respectivamente) se colocam numa espécie de paralelo teórico, há uma contraface de ideias que se interpenetram na leitura das práticas cotidianas. É por aqui que as heterotopias de Foucault vêm ao encontro do espaço vivido e das operações mudas dos praticantes em que Certeau investe; é por aqui que suas astúcias, a rede das táticas invisíveis de subversão da ordem sob seu próprio domínio se articula com a atitude descrita por Foucault como contraconduta. Obviamente, os conceitos nunca se equivalem, mas produzem entre si relações que modificam sua posição, alteram seu sentido; há que se pensar que problemas estas relações podem suscitar e diante de que práticas. 
Se por um lado a racionalidade das estratégias - plano sobre o qual é possível determinar e isolar um sujeito ou polo de querer e poder, que mantém uma relação de exterioridade com seus alvos e ameaças (Certeau, 2009) - normatiza a vida, por outro as operações dos viventes estão prenhes de astúcias que tiram proveito do acontecimento, dos elementos à disposição, movimentos e forças quase sempre estranhas, vindas justo da fonte que pretende exercer controle. "A ordem efetiva das coisas é justamente aquilo que as táticas 'populares' desviam para fins próprios, sem a ilusão que mude proximamente.” (Certeau, 2009, p. 83).

Tal é a aposta de Certeau, ilustrada na análise de algumas práticas cotidianas: falar, ler, caminhar, comprar, habitar, cozinhar... Cada um destes fazeres “banais" é povoado por meticulosas táticas - movimentos sem domínio próprio, que aproveitam o imprevisto e a transitoriedade, a ocasião e a circunstância, burlando o cálculo das estratégias - que funcionam em silêncio, muitas vezes sem que o próprio praticante tenha consciência de que subverte algo na ordem estabelecida (Certeau, 2009). Não se trata, pois, de uma intencionalidade racionalmente contestatória, mas de um saber-fazer que não se ocupa de sua auto-afirmação enquanto tal, que é efêmero e em certa medida inconsciente, o que em nada o impede de produzir efeitos. Aliás, é exatamente esta condição precária, sem “domínio próprio", sem consciência de si que torna possíveis as subversões subordinadas - talvez seja precisamente o inverso - que interessam a Certeau. É o modo como os "fracos" e "dominados" inventam artes de fazer que impele à elaboração de uma política das astúcias (Certeau, 2009).

\begin{abstract}
$\mathrm{Eu}$ gostaria de acompanhar alguns dos procedimentos - multiformes, resistentes, astuciosos e teimosos - que escapam à disciplina sem ficarem mesmo assim foram do campo onde se exerce, e que deveriam levar a uma teoria das práticas cotidianas, do espaço vivido e de uma inquietante familiaridade da cidade (Certeau, 2009, p. 163).
\end{abstract}

Uma marca forte do trabalho de Certeau sobre o cotidiano é a correspondência do procedimento de pesquisa com o objeto em questão (no seu caso, as astúcias de usuários e consumidores, do homem ordinário). A arte de dizer estas maneiras de fazer já as exerce, as dá corpo, sem o quê seu propósito se esvazia, se esteriliza, perde a força da operação que põe em evidência, se perde da prática que analisa. Certeau diz que é necessário "reaprender operações comuns e fazer da análise uma variante do 
seu objeto." (Certeau, 2009, p. 35, grifo nosso).

Contudo, esta correspondência não é uma indiferenciação. Trata-se de fazer das técnicas de pesquisa algo que "repete diferindo" aquilo que estuda, que simula as potências do campo problemático em questão no próprio trabalho do pesquisador, no seu modo de pensar, analisar e transmitir aquilo que investiga, produzindo assim composições originais e efeitos singulares. No limite, é a pesquisa que assume, uma vez mais, seus traços de arte. Neste ponto, encontramos um fosso que ainda intimida pesquisadores das ciências humanas, cavado entre a ciência e as demais práticas sociais.

Desde que a cientificidade se atribuiu lugares próprios e apropriáveis por projetos racionais capazes de colocar zombeteiramente os seus modos de proceder, os seus objetos formais e as condições de sua falsificação, desde que ela se fundou como uma pluralidade de campos limitados e distintos, em suma, desde que não é mais do tipo teológico, a ciência constituiu o todo como o seu resto, e este resto se tornou o que agora denominamos a cultura (Certeau, 2009, p. 62 , grifos do autor).

Interessar-se pelo resto das disciplinas, a matéria rejeitada pela industriosidade científica, a sucata dispersa na vida cotidiana: é assim que Certeau devém sucateiro, catador dos desperdícios nesse "terreno onde já não há mais discursos" (Certeau, 2009, p. 123). Mas também por seu modo de dizer o que pesquisa. Servindo-se de conceitos gastos como os de estratégia, tática, uso e consumo, Certeau procede à tentativa de não se distanciar da linguagem ordinária em que as práticas se desenrolam. Em todo caso, diz algo novo a partir de velhas peças, compõe um maquinário inédito com componentes recondicionados.

O procedimento certeauniano, como aqueles por ele analisados, é dotado de uma maneira, um jeito, um estilo que lhe confere singularidade e, da mesma forma, de uma técnica meticulosa e discreta, que paulatinamente se apropria do objeto de análise e torna também seu o movimento das práticas pesquisadas. Inventa para si uma arte de pesquisar cheia de astúcias, no jogo em que aproveita na escrita as frestas do estrategismo teórico para produzir um pensamento do impensado, o cotidiano e suas artes. Certeau adverte que a paisagem imaginária de uma pesquisa é importante, ainda que não contenha "rigor" em si mesma. É que tradicionalmente, a questão do método - e os dilemas que ela introduz na relação entre o conhecimento e as outras práticas é vista como a exigência de "um discurso que organiza a maneira de pensar em maneira de fazer, em gestão racional de 
uma produção e em operação regulada sobre campos apropriados" (Certeau, 2009, p. 127-8), excluindo todo o universo cultural que permeia cada gesto e pensamento do pesquisador, as fantasias, as experiências sem currículo, as manhas.

O que leva Certeau a insistir em um procedimento de pesquisa que partilhe do movimento que anima as próprias táticas, que seja portador das astúcias que nelas encontra é uma atitude política em relação ao conhecimento e aos efeitos que ele produz. Por este motivo é que sua pesquisa não consiste num levantamento sistemático de todas as táticas de resistência dos homens ordinários, consumidores, praticantes. Essa vontade - estratégica - de totalizar, a que serve? Como responder a ela, senão por meio das esquivas e golpes de astúcia, por uma política de pesquisa obstinada em fazer transitar em seu próprio funcionamento as operatórias que investiga?

$\mathrm{Na}$ instituição a servir se insinuam assim um estilo de trocas sociais, um estilo de invenções técnicas, e um estilo de resistência moral, isto é, uma economia do "dom" (de generosidades como revanches), uma estética de "golpes" (de operações de artistas) e uma ética da tenacidade (mil maneiras de negar à ordem estabelecida o estatuto de lei, de sentido ou fatalidade). A cultura "popular" seria isso, e não um corpo considerado estranho, estraçalhado a fim de ser exposto, tratado e

\author{
"citado" por um sistema que reproduz, \\ com os objetos, a situação que impõe aos \\ vivos (Certeau, 2009, p. 83, grifos do \\ autor.).
}

O rumo incerto que esta postura implica atravessa cada ato dos ofícios de pesquisa, seus espaços, suas relações, suas tarefas. $\mathrm{Na}$ escrita, prática comumente destinada ao império da função de comunicar, parte desta economia generosa, desta estética de astúcias e de uma ética da teimosia estão ao alcance das mãos, literalmente: são elas, afinal, que silenciosamente tocam as letras na direção do texto por escrever. Se tudo o que um trabalho de pesquisa produz resulta em textualidades diversas, talvez caiba pensar a presença da escrita entre os problemas capitais desta prática.

\section{A Pesquisa em Suas Técnicas}

O este arranjo de ideias nos permite pensar quanto à prática cotidiana do pesquisador que se ocupa dos processos sociais? O caminho esboçado deixa ver que os riscos do percurso estão sempre à espreita de nosso passo; evitá-los em busca de segurança faz perder de vista as possibilidades de encontrar rotas rumo a novas paragens. Vale mais acompanhar os riscos, como rastros, se embrenhar neles, carregar consigo as marcas que se imprimem no itinerário deste fazer incerto 
que é pesquisar. Uma leitura é exatamente isso, acompanhar os riscos dos outros, se embolar na sua trama, perder-se em terra estrangeira, dispor-se a novos encontros. Simulação, artesania. Só por meio do artifício, ensina Malinowski (1978), é que "fazemos tecnologia", inventamos uma arte de pesquisa; só assim nos tornamos capazes de fabricar instrumentos, conceitos, técnicas, estilos, astúcias, numa palavra, só assim a pesquisa se torna, de fato, uma experiência.

A importância do procedimento num sentido amplo, tanto das técnicas quanto da atitude, da disposição do pesquisador - na prática de pesquisa extrapola o horizonte metodológico, na forma que institucionalmente o conhecemos. Não obstante a existência de "disciplinas" de metodologia, a partilha do saber-fazer por vezes circula alhures, quiçá nunca apareça onde se pretende ensiná-lo. Se a prática de pesquisa exige plena atenção aos "imponderáveis da vida real" (Malinowski, 1978, p. 29), difíceis de prever nos ementários, não é preciso se opor às disciplinas para apreender 0 sentido desta problematização, mas sim manter juntos imaginário e estratégia de trabalho em cada ato da pesquisa. Como propõe Certeau, os desvios e as manhas sempre existiram por toda parte, e operam aí mesmo onde toda previsão ainda deixa escapar os burburinhos da invenção.
A graça da pesquisa do cotidiano não está nos "fatos", mas no modo de se acercar deles (Pais, 2007; Ferreri \& Nobre, 2010), de problematizá-los, na maneira de torná-los dizíveis, visíveis, pensáveis. Este "modo de fazer" evoca a partilha de uma experiência, que além ou aquém dos "dados", da "informação", ou da "verdade" tem outras funções a desempenhar no universo da pesquisa. Trata-se de uma política de conhecimento que tem seu primado na partilha dos percursos e procedimentos que configuram a prática de pesquisa. Seja em Simmel ou Mauss, em Foucault ou Certeau, o que se coloca em evidência neste texto é mais o modo como estes pensadores - através de seus campos problemáticos e dos conceitos que criam para dar-lhes consistência - empreendem a tarefa de criar artes de pensar, pesquisar e dizer que só tem efeito se concretamente experimentadas nos trajetos singulares de pesquisa que se apropriam e partilham de suas contribuições.

A superficialidade atribuída ao cotidiano não é uma qualidade intrínseca, mas uma situação, diz Pais (2007). Ao raso do cotidiano, entretanto, o que se opõe? As profundezas do extraordinário? Há que se perguntar se bastaria o estranhamento de Robinson Crusoé, recriado por Michel Tournier em Sexta-Feira ou Os Limbos do Pacífico, para desviar o curso deste maniqueísmo, "que valoriza cegamente a 
profundidade à custa da superfície e que faz com que 'superficial' signifique não 'de vasta dimensão', mas, sim, 'de pouca profundidade', enquanto 'profundo' significa, pelo contrário, 'de grande profundidade' e não 'de fraca superfície"” (Tournier, 1985, p. 60). Rasar pela superfície dos dias, pelas horas em que "nada se passa", promover deambulações vadias, sentir o gosto sem gosto do tédio, ocupar-se da vagabundagem - como João do Rio (2008), Baudelaire (2010), Pessoa (2006; 2007), Benjamin (1995; 2007) e tantos outros casos - e fazer disso um procedimento de pesquisa. $\mathrm{O}$ que se perde, o que se ganha? Só quem experimenta é capaz de responder. A técnica do artesão precisa, para ser o que é, de alguma comunidade com o jogo ou o brinquedo, de alguma ludicidade:

Ludicidade que não implica falta de seriedade, mas sim, muito mais, uma prudência: a de evitarmos sermos capturados pela sedução das forças reativas tão fortemente presentes na moral de ressentimento e na razão cínica que permeiam nossa cultura. Para compreender o sentido de sua eficácia, de seu poder de agenciamento, é necessário procurá-la não só em suas linguagens e proposições, mas também no homem que as acolhe e com elas constrói seus referentes cotidianos (Rodrigues, 2002, p. 52-3).
Esta perspectiva aponta para o desenho de um risco para a pesquisa do cotidiano, que não poderá tomar a cidade como mero dado espacial ou evidência geográfica, mas como rede de práticas, palco de embates, gestões e teimosias. Tal o sentido de eleger processos que engendram a experiência urbana na constituição do corpo, nos procedimentos de enfrentamento da rotina e nos espaços praticados da cidade. Este tipo de articulação desvia de uma subdivisão disciplinar - um "especialismo" urbano que concentre estas pesquisas, já tão tensionadas por fragmentações -, mas a produção de análises que contemplem a experiência de habitar as cidades (e das cidades que nos habitam) como campo problemático.

\section{Notas}

${ }^{1}$ Entretanto, é preciso ressaltar, como o fez o próprio Foucault, que “[...] os procedimentos de poder colocados em prática nas sociedades modernas são bem mais numerosos, diversos e ricos. Seria falso dizer que o princípio da visibilidade comanda toda a tecnologia do poder desde o século XIX” (Foucault, 1984, p. 211). 


\section{Referências}

Baudelaire, C. (2010). O pintor e a vida moderna. (T. Tadeu, trad.). Belo Horizonte: Autêntica.

Benjamin, W. (1994). O narrador. Considerações sobre a obra de Nicolai Leskov. Em Magia e técnica, arte $e$ política: ensaios sobre literatura e história da cultura. (pp. 91-107). (7a ed.). (S. P. Rouanet, trad.). São Paulo: Brasiliense.

Benjamin, W. (1995). Rua de mão única. Obras Escolhidas II. (R. R. Torres Filho \& J. C. M. Barbosa, trad.). São Paulo: Brasiliense.

Benjamin, W. (2007). Passagens. (W. Bolle \& O. C. F. Matos, org. ed. bras.). (I. Aron \& C. P. B. Mourão, trad.). Belo Horizonte: Editora UFMG.

Berger, P. \& Luckmann, T. (1985). A construção social da realidade. Tratado de sociologia do conhecimento. (25a ed.). (F. S. Fernandes, trad.). Petrópolis, RJ: Vozes.

Certeau, M. (2009). A invenção do cotidiano 1: artes de fazer. (16a ed.). (E. F. Alves, trad.). Petrópolis, RJ: Vozes.

Escóssia, L. (1999). Relação homem-técnica e processo de individuação. São Critóvão, SE: Editora UFS.

Ferreri, M. .A. \& Nobre, M. T. (2010). A festa dos canos e a noite das facadas: a pesquisa etnográfica e o estatuto das falas dispersas no campo. Estudos $e$ Pesquisas em Psicologia, 10(1), 264-80.

Foucault, M. (1984). O olho do poder. Em Microfísica do poder. (pp. 209227). (4a ed.). (R. Machado, trad. e org.). Rio de Janeiro: Graal.

Foucault, M. (1987). Vigiar $e$ punir. Nascimento da prisão. (R. Ramalhete, trad.). Petrópolis, RJ: Vozes.

Foucault, M. (1995). Sobre a genealogia da ética: uma revisão do trabalho. Em H. Dreyfus \& Paul Rabinow. Michel Foucault: uma trajetória filosófica. Para além do estruturalismo e da hermenêutica. (pp. 253-278). (V. P. Carrero, trad.). Rio de Janeiro: Forense Universitária.

Foucault, M. (1999c). As palavrase as coisas: uma arqueologia das ciências humanas. (8a ed.). (S. T. Muchail, trad.). São Paulo: Martins Fontes.

Foucault, M. (2006). Outros Espaços. Em Ditos \& Escritos III Estética: literatura e pintura, música e cinema. (pp. 411-422). (I. A. D. Barbosa, trad.). Rio de Janeiro: Forense Universitária.

Foucault, M. (2008). Segurança, Território, População: curso dado no Collège de France (1977-1978). (E. Brandão, trad.). São Paulo: Martins Fontes.

Lévi-Strauss, C. (2003). Introdução à obra de Marcel Mauss. Em Mauss, M. (2003). As técnicas do corpo. Em 
Sociologia e antropologia. (pp. 11-46). (P. Neves, trad.). São Paulo: Cosac Naify.

Malinowski, B. (1978). Introdução: tema, método e objetivo desta pesquisa. Em Os Argonautas do Pacífico Ocidental. (pp. 17-34). (Coleção Os Pensadores). São Paulo: Abril.

Mauss, M. (2003). As técnicas do corpo. Em Sociologia e antropologia. (pp. 399-422). (P. Neves, trad.). São Paulo: Cosac Naify.

Pais, J. M. (2007). Sociologia da vida quotidiana. Teorias, métodos e estudos de caso. (3a ed.). Lisboa, Portugal: Imprensa de Ciências Sociais.

Pessoa, F. (2006). O livro do desassossego. Composto por Bernardo Soares, ajudante de guarda-livros na cidade de Lisboa. (R. Zenith, org). São Paulo: Companhia das Letras.

Pessoa, F. (2007). Poesia completa de Álvaro de Campos. (T. R. Lopes, org.). São Paulo: Companhia das Letras.
Rio, J. (2008). A alma encantadora das ruas. Crônicas. (R. Antelo, org.). São Paulo: Companhia das Letras.

Rodrigues, V. A. (2002). Corpo, técnica e mídia: simulações de potênciaVol. 1. (2 volumes). Dissertação de Mestrado, Faculdade de Comunicação Social Cásper Líbero, São Paulo.

Simmel, G. (2005). As grandes cidades e a vida do espírito (1903). (L. Waizbort, trad.). Mana, 11(2), 577-591.

Tournier, M. (1985). Sexta-Feira ou os limbos do Pacífico. (F. Botelho, trad.). São Paulo: Difel.

$\overline{\text { Eder Amaral e Silva - Doutorando em }}$ Psicologia Social na UERJ - Universidade Estadual do Rio de Janeiro, RJ, Brasil.

E-mail: eder_as@yahoo.com.br. 